\title{
AUDIT APLIKASI DEVELOP INTERNAL DENGAN COBIT 4.1 (STUDI KASUS : PT CENTRAL MEGA KENCANA)
}

\section{Audit of Internal Develop Application (Case: PT Central Mega Kencana)}

\author{
Kevin Christianto ${ }^{\text {1) }}$, Leonard Davinci ${ }^{2)}$, Titus Zefanya Ivgantius ${ }^{3)}$, \\ Yosep Prasetyo Setiawan ${ }^{4)}$, Timothy Jason Andreas ${ }^{5)}$ \\ ${ }^{1,2,3,4,5)}$ Program Studi Sistem Informasi, Universitas Bunda Mulia, Jakarta
}

Diterima 18 Juli 2019 / Disetujui 14 Agustus 2019

\begin{abstract}
Information technology is an important part for companies or institutions as a thing that can support the achievement of strategic plans to achieve the goals of vision, mission and corporate goals PT.Central Mega Kencana. By increasing the role of information technology, investment in information technology is getting bigger and more complex in its management. Therefore To organize, evaluate the required information technology governance by using standardized obeject approach. The governance of this information system audit is done using the AI (acquired and implemented) Cobit 4.1 framework and the final result of this analysis yields how far the level of maturity level governance maturity and recommendations for PT. Central Mega Kencana proposed. Keywords: COBIT 4.1, Tata Kelola,Audit Sistem Informasi,PT. Central Mega Kencana
\end{abstract}

\begin{abstract}
ABSTRAK
Teknologi informasi merupakan suatu bagian yang penting bagi perusahaan atau lembaga sebagai suatu hal yang dapat mendukung pencapaian rencana strategis untuk mencapai sasaran visi, misi dan tujuan perusahaan PT.Central Mega Kencana. Dengan meningkatkan peran teknologi informasi maka investasi di bidang teknologi informasi semakin besar dan semakin kompleks dalam pengelolaanya. Oleh karena itu Untuk mengatur, mengevaluasi dibutuhkan tata kelola teknologi informasi dengan mengunakan pendekatan obejektif yang standar. Tata kelola audit sistem informasi ini dilakukan dengan menggunakan framework Cobit 4.1 didomain AI (acquired and implement) dan hasil akhir dari analisis ini menghasilkan seberapa jauh tingkat dari kematangan tata kelola maturity level dan rekomendasi bagi PT. Central Mega Kencana yang diusulkan.
\end{abstract}

Kata Kunci: COBIT 4.1, Tata Kelola,Audit Sistem Informasi, PT. Central Mega Kencana

\footnotetext{
*Korespondensi Penulis:

E-mail: kevin.hikoza@gmail.com
} 


\section{PENDAHULUAN}

Seiring dengan perkembangan zaman, kebutuhan akan teknologi tidak dapat dihindari karena kegunaaanya untuk membantu kita dalam menjalankan segala kegiatan, baik itu dari segi pendidikan, kesehatan bahkan ekonomi pun ikut beradaptasi dan terus berkembang saat ini (Fenny dan Andry, 2017). Teknologi yang sering kita gunakan tidak lain banyak diterapkan untuk kebutuhan masyarakat seperti halnya komputer, laptop, bahkan handphone menjadi pilihan dalam penerapan suatu teknologi. Sehingga TI dipercaya dapat membantu meningkatkan efisiensi dan efektifitas proses-proses bisnis organisasi dalam mencapai tujuannya (Ekowansyah, dkk, 2017). Kemudian didalam alat eletronik seperti handphone atau komputer tersebut kita akan menemukan suatu aplikasi software dimana aplikasi tersebut sebagai perantara untuk membantu kita dalam menjalankan segala kegiatan atau aktivitas sehari-hari.

Aplikasi software tersebut banyak digunakan diberbagai alat elektronik termasuk diperusahaan-perusahaan dan industri sekarang ini, selain untuk mempermudah pekerja dan pimpinan perusahaan dalam mengelola perusahaannya, aplikasi juga menunjang segala kegiatan yang pekerja telah lakukan seperti halnya menyimpan data-data penting perusahaan dan mencatat segala rekaman data-data lain di dalam software tersebut, sehingga dengan demikian dapat diartikan bahwa aplikasi adalah sebuah layanan Sistem Informasi dikatakan baik dan layak apabila sudah memenuhi standard dan adanya tata kelola IT yang baik pula serta dilihat dari keefektifan penggunaan aplikasi.

Setiap perusahaan saat ini sudah mengimplementasikan teknologi informasi dalam menjalankan bisnisnya, baik dengan investasi TI yang minim maupun investasi yang besar. Perusahaan sadar bahwa penggunaan TI pada operasional bisnis mereka. Untuk setiap investasi yang dilakukan perlu diketahui atau diukur tingkat efektivitas dan efisiensi yang dihasilkan, agar perusahaan benar-benar merasakan nilai dari implementasi TI tersebut (Wella, 2016).

Peranan TI dalam membantu perusahaan tidak diragukan lagi dalam pencapaian suatu tujuan salah satunya yang dilakukan oleh PT Central Mega Kencana yang memulai bisnisnya pada tahun 1970an Akhir, Perusahaan ini didirikan. Awal mula perusahaan memulai bisnis perhiasan berlian yakni sebagai wholesaler perhiasan berlian pada industri luxury goods. Perusahaan mengoperasikan 4 brand pada bisnis retailer yakni Frank \& Co, Mondial, Miss Mondial, dan The Palace, dan tetap menjalankan bisnis wholesaler. Tentu saja PT CMK ini menggunakan sebuah aplikasi untuk membantu memudahkan terintergrasinya semua badan organisasi internal.

Di sisi lain tata kelola dan tantangan manajemen perusahaan sudah semakin kompleks, hal ini menyebabkan semua perusahaan harus benar-benar mengantisipasi semua kelemahan sisem informasi yang mereka miliki. Maka dari itu perlu adanya audit sistem informasi yang berjalan di perusahaan tersebut (Sulaeman, 2015).

Untuk itu, agar usaha pemanfaatan TI berjalan seperti yang diharapkan tentunya diperlukan tata kelola TI yang baik. Keberhasilan IT Governance (tata kelola TI) sangat ditentukan oleh keselarasan penerapan TI dan tujuan organisasi. TI menjadi isu penting dalam strategi pengembangan dan peningkatan kinerja organisasi. Perubahan teknologi yang cepat menuntut keputusan TI yang tepat waktu (Setiawan dan Mustofa, 2013). 


\begin{abstract}
Dengan peranan teknologi informasi sebagai alat pengambilan keputusan, maka perlu dilakukan penatakelolaan IT di organisasi untuk memastikan bahwa penerapan IT organisasi sudah dilakukan dengan benar dan terarah, yang meliputi adanya visi, misi, perencanaan IT, dan kepedulian dari pimpinan organisasi. Untuk melakukan hal tersebut diperlukan adanya audit sistem informasi. Audit sistem informasi berfungsi untuk memastikan bahwa IT organisasi menggunakan sumber daya secara efisien, mengamankan asset organisasi, menjaga intergritas dan keamanan data organisasi, dan mencapai tujuan organisasi secara efektif. untuk melakukan audit terhadap kinerja pengelolaan IT suatu organisasi atau institusi, saat ini banyak framework yang dapat digunakan. Salah satu diantaranya adalah COBIT.
\end{abstract}

Standar COBIT dipilih karena dapat memberikan gambaran paling detail mengenai strategi dan pengaturan proses TI yang mendukung strategi bisnis, dimana kerangka kerjanya terdiri dari 4 domain. Sehingga dapat dijelaskan bahwa pengertian COBIT adalah sekumpulan dokumentasi best practices untuk IT Governance yang dapatmembantu auditor, pengguna (user), dan manajemen, untuk menjembatani gap antara risiko bisnis, kebutuhan control dan masalah-masalah teknis TI. COBIT bermanfaat bagi auditor karena merupakan teknik yang dapat membantu dalam identifikasi IT controls issues. COBIT berguna bagi IT users karena memperoleh keyakinan atas kehandalan sistem aplikasi yang dipergunakan. Sedangkan para manajer memperoleh manfaat dalam keputusan investasi di bidang TI serta infrastrukturnya, menyusun strategic IT plan, menentukan information architecture,dan keputusan atas procurement (pengadaan atau pembelian) mesin.
COBIT mendukung manajemen dalam mengoptimalkan investasi TI-nya melalui ukuran-ukuran dan pengukuran yang akan memberikan sinyal bahaya bila suatu kesalahan atau risiko akan atau sedang terjadi. Manajemen harus memastikan bahwa sistem kendali internal perusahaan bekerja dengan baik, artinya dapat mendukung proses bisnis perusahaan yang secara jelas menggambarkan bagaimana setiap aktivitas kontrol individual memenuhi tuntutan dan ke butuhan informasi serta efeknya terhadap sumber daya TI perusahaan. Sumber daya TI merupakan suatu elemen yang sangat disoroti COBIT, termasuk pemenuhan kebutuhan bisnis terhadap efektivitas, efisiensi, kerahasiaan, keterpaduan, ketersediaan, kepatuhan pada kebijakan atau aturan dan keandalan informasi (Subakti, 2012).

Adapun tujuan audit sistem informasi ini adalah untuk mengukur tingkat kematangan implementasi teknologi informasi pada domain Acquire and Implement dengan menggunakan kerangka kerja COBIT 4.1. Salah satu standar penting dan efektif untuk diterapkan adalah Control Objectives for Information and Related Technology (COBIT). COBIT dikeluarkan oleh ISACA pada 1992 dan merupakan standar yang berorientasi pada proses, berfokus pada sasaran bisnis, dan merupakan alat manajerial dan teknikal untuk unit TI (Tjhin, 2014).

Melihat bahwa PT Central Mega Kencana adalah perusahaan yang bergerak di bidang berlian ,maka kami ingin melakukan analisis terhadap aplikasi developer internal dengan menggunakan COBIT Framework 4.1 domain AI sebagai bahan acuan agar kegiatan audit dapat dilaksanakan, sehingga peneliti tertarik untuk mengakomodasi semua itu dengan mengambil judul penelitian "Audit Aplikasi 
Develop Internal Dengan Framework Cobit 4.1".

\section{METODOLOGI}

\section{A. Subjek Penelitian}

Untuk melaksanakan observasi yang memerlukan data atau informasi tentang suatu hal, penulis gunakan objek penelitian adalah seorang supervisor IT Sistem Analisis di divisi IT pada PT Central Mega Kencana.

\section{B. Tahapan Penelitian}

Adapun tahapan-tahapan dalam pelaksanaan penelitian ini menjelaskan beberapa rangkaian tahapan mengenai perencanaan, pelaksanaan, pengumpulan data, sampai dengan pemnyusunan pelaporan. Adapun tahapan tersebut adalah:

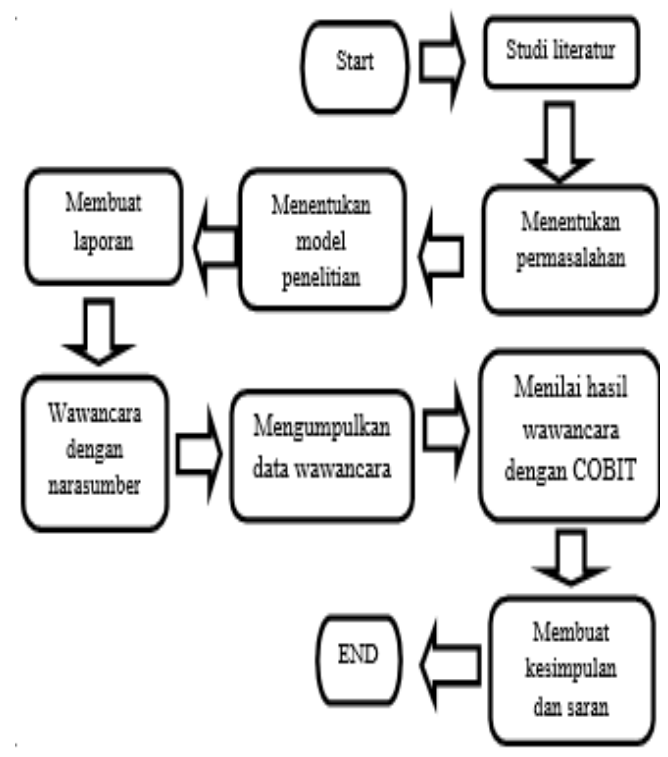

\section{Gambar 1 Tahapan Penelitian}

\section{Teknik pengumpulan data}

Wawancara merupakan sebuah langkah memperoleh informasi dengan metode tanya-jawab empat mata antara pewawancara dengan responden atau orang yang diwawancarai, dengan atau tanpa menggunakan pedoman wawancara.
Wawancara dilaksanakan dengan bertujuan menghasilkan informasi sebagai pendukung hasil kuesioner. Wawancara dilakukan untuk mendapatkan informasi lebih lengkap mengenai masalah yang diteliti yang tidak tertangkap melalui kuesioner.

\section{HASIL DAN PEMBAHASAN}

Untuk mewujudkan strategi IT, solusi yang dibutuhkan untuk di identifikasi seperti mengimplementasi dan mengintegrasi kedalam proses bisnis. Selain itu, perubahan dan pemeliharaan sistem yang dicangkup oleh domain ini untuk memastikan solusinya terus memenuhi tujuan bisnis (Andry, dan Christianto, 2018)

\section{A. AI1 Identify-Automated Solutions}

Yang dibutuhkan oleh sebuah aplikasi baru atau suatu fungsi membutuhkan analisis sebelum memperoleh bisnis dengan pendekatan secara efisien dan efektif. Proses ini menutupi definisi kebutuhan dimana pertimbangan dari sumber alternatif , ulasan dari teknologi dan ekonomi yang kemungkinan dapat terjadi, eksekusi dari sebuah analisis resiko dan biaya pemanfaatan serta kesimpulan akhir dari sebuah keputusan "to make" dan "buy". Semua proses ini memungkinkan organisasi untuk meminimalkan solusi biaya acquire and implement guna mencapai proses bisnis.

Berdasarkan temuan masalah yang didapatkan makan peneliti memberikan nilai-nilai pada masing-masing proses yang terdapat pada sub-domain AI1: (lihat tabel $1)$. 


\section{Tabel 1 Maturity level AI1}

\begin{tabular}{|c|l|c|}
\hline Domain & \multicolumn{1}{|c|}{ Keterangan } & Hasil \\
\hline AI 1.1 & $\begin{array}{l}\text { Definition and } \\
\text { Maintenance of } \\
\text { Business-Functional and } \\
\text { Technical Requirements }\end{array}$ & 2 \\
\hline AI 1.2 & $\begin{array}{l}\text { Risk Analysis Report } \\
\text { AI 1.3 }\end{array}$ & $\begin{array}{l}\text { Feasibility Study and } \\
\text { Formulation } \\
\text { Alternative Courses of } \\
\text { Action }\end{array}$ \\
\hline AI 1.4 & $\begin{array}{l}\text { Requirements and } \\
\text { Feasibility Decision and } \\
\text { Approval }\end{array}$ & \\
\hline & Rata-rata & 2 \\
\hline
\end{tabular}

Rata-rata hasil maturity-Level pada proses ini adalah 2.25. Dianggap termasuk ke dalam Repeatable but intuitive.

\section{B. AI2 Acquire and Maintain Application- Software}

Aplikasi dibuat tersedia sejalan dengan persyaratan bisnis. Proses ini meliputi desain aplikasi, ketepatan dari aplikasi control dan keamanan persyaratan, serta pengembangan dan konfigurasi sejalan dengan standar, lihat table 2 .

Tabel 2 Maturity level AI2

\begin{tabular}{|c|c|c|}
\hline Domain & Keterangan & Hasil \\
\hline AI 2.1 & High-level Design & 2 \\
\hline AI 2.2 & Detailed Design & 2 \\
\hline AI 2.3 & $\begin{array}{l}\text { Application-Control and } \\
\text { Auditability }\end{array}$ & 3 \\
\hline AI 2.4 & $\begin{array}{l}\text { Application Security and } \\
\text { Availability }\end{array}$ & 2 \\
\hline AI 2.5 & $\begin{array}{l}\text { Configuration } \\
\text { Implementation and } \\
\text { Acquired Application } \\
\text { Software }\end{array}$ & 3 \\
\hline AI 2.6 & $\begin{array}{l}\text { Major Upgrades to } \\
\text { Existing-Systems }\end{array}$ & 3 \\
\hline AI 2.7 & $\begin{array}{l}\text { Development-of } \\
\text { Application Software }\end{array}$ & 3 \\
\hline AI 2.8 & $\begin{array}{l}\text { Development-of } \\
\text { Application Software }\end{array}$ & 4 \\
\hline AI 2.9 & $\begin{array}{l}\text { Applications Requirements } \\
\text { Management }\end{array}$ & 3 \\
\hline AI 2.10 & Application & 2 \\
\hline
\end{tabular}

\begin{tabular}{|l|l|c|} 
& Maintenance & \\
\hline & Rata-rata & 2.7 \\
\hline
\end{tabular}

Rata-rata hasil maturity-Level pada proses ini adalah 2.7. Dianggap termasuk ke dalam Repeatable but intuitive.

\section{AI3 Acquire and Maintain Technology- Infrastructure}

Organisasi memiliki proses untuk memperoleh, mengimplementasi dan meningkatkan teknologi infrastruktur. Hal ini membutuhkan sebuah rencana pendekatan untuk memperoleh, memelihara dan melindungi infrastruktur sejalan dengan kesepakatan strategi teknologi. Hal ini meyakinkan bahwa teknologi mendukung untuk bisnis aplikasi.

Tabel 3 Maturity level AI3

\begin{tabular}{|c|l|c|}
\hline Domain & Keterangan & Hasil \\
\hline AI 3.1 & $\begin{array}{l}\text { Technological- } \\
\text { Infrastructure Acquisition } \\
\text { Plan }\end{array}$ & 2 \\
\hline AI 3.2 & $\begin{array}{l}\text { Infrastructure-Resource } \\
\text { Protection and Availability }\end{array}$ & 2 \\
\hline AI 3.3 & $\begin{array}{l}\text { Infrastructure } \\
\text { Maintenance }\end{array}$ & 3 \\
\hline AI3.4 & $\begin{array}{l}\text { Feasibility } \\
\text { Environment }\end{array}$ & 2 \\
\hline & Rata-rata & 2.25 \\
\hline
\end{tabular}

Rata-rata hasil maturity-Level pada proses ini adalah 2,25. Dianggap termasuk ke dalam repeatable but intuitive.

\section{AI4 Enable-Operation and Use}

keahlian mengenai sistem baru dibuat tersedia. Proses ini mensyaratkan produksi dokumentasi dan pengguna manual IT serta memastikan pelatihan operasi aplikasi dan infrastruktur berjalan dengan benar, lihat tabel 4 .

\section{Tabel 4 Maturity level AI4}

\begin{tabular}{|c|l|c|}
\hline Domain & Keterangan & $\begin{array}{l}\text { Hasil } \\
\text { perhitun } \\
\text { gan }\end{array}$ \\
\hline AI 4.1 & $\begin{array}{l}\text { Planning for Operational } \\
\text { Solutions }\end{array}$ & 3 \\
\hline
\end{tabular}




\begin{tabular}{|c|l|c|} 
AI 4.2 & $\begin{array}{l}\text { Knowledge Transfer to } \\
\text { Business Management }\end{array}$ & 3 \\
\hline AI 4.3 & $\begin{array}{l}\text { Knowledge Transfer to } \\
\text { End Users }\end{array}$ & 4 \\
\hline AI 4.4 & $\begin{array}{l}\text { Knowledge Transfer to } \\
\text { Operations and Support } \\
\text { Staff }\end{array}$ & 3 \\
\hline & Rata-rata & 3.25 \\
\hline
\end{tabular}

Rata-rata maturity level pada proses ini adalah 3. Dianggap termasuk ke dalam Defined.

\section{E. AI5 Procure-IT Resources}

Tabel 5 Maturity level AI5

\begin{tabular}{|c|l|c|}
\hline Domain & \multicolumn{1}{|c|}{ Keterangan } & $\begin{array}{c}\text { Hasil } \\
\text { perhitun } \\
\text { gan }\end{array}$ \\
\hline AI 5.1 & Procurement Control & 3 \\
\hline AI 5.2 & $\begin{array}{l}\text { Supplier Contract } \\
\text { Management }\end{array}$ & 2 \\
\hline AI 5.3 & Supplier Selection & 2 \\
\hline AI 5.4 & IT-Resources Acquisition & 2 \\
\hline & Rata-rata & 2.25 \\
\hline
\end{tabular}

Sumber daya IT, hardware, perangkat lunak, dan layanan perlu diperoleh. masalah ini memerlukan pengertian dan penegakan prosedur pengadaan, pemilihan vendor serta pengaturan kontrak. Memastikan bahwa organisasi memiliki semua sumber daya TI yang dibutuhkan secara tepat waktu dan hemat biaya.

Rata-rata maturity level yang didapat adalah 2,25. Dianggap termasuk ke dalam repeatable but intuitive.

\section{F. AI6 Manage-Changes}

Semua perubahan, termasuk perubahan darurat terkait dengan infrastruktur dan program dalam produksi lingkungan selaku resmi diatur dengan cara terkendali. Perubahan(termasuk perubahan pada metode, teknik, sistem dan layanan parameter) dicatat, dinilai, dan disahkan sebelum implementasi dan dilihat terhadap hasil-nilai yang direncanakan, lihat tabel 6 .
Tabel 6 Maturity level AI6

\begin{tabular}{|c|l|c|}
\hline Domain & \multicolumn{1}{|c|}{ Keterangan } & $\begin{array}{c}\text { Hasil } \\
\text { perhitun } \\
\text { gan }\end{array}$ \\
\hline AI 6.1 & $\begin{array}{l}\text { Change Standards and } \\
\text { Procedures }\end{array}$ & 3 \\
\hline AI 6.2 & $\begin{array}{l}\text { Impact Assessment, } \\
\text { Prioritisation and } \\
\text { Authorisation }\end{array}$ & 3 \\
\hline AI 6.3 & $\begin{array}{l}\text { Emergency Changes } \\
\text { AI 6.4 }\end{array}$ & $\begin{array}{l}\text { Change Status Tracking } \\
\text { and Reporting }\end{array}$ \\
\hline AI 6.5 & $\begin{array}{l}\text { Change Closure and } \\
\text { Documentation } \\
\text { Rata-rata }\end{array}$ & 2 \\
\hline
\end{tabular}

Rata-rata hasil maturity-Level yang didapatkan adalah 3. Dianggap termasuk ke dalam Defined.

\section{G. AI7 Install and Acredit Solutions and Changes}

Tabel 7 Maturity level AI7

\begin{tabular}{|c|l|c|}
\hline Domain & \multicolumn{1}{|c|}{ Keterangan } & $\begin{array}{c}\text { Hasil } \\
\text { perhitungan }\end{array}$ \\
\hline AI 7.1 & Traning & 4 \\
\hline AI 7.2 & Test Plan & 4 \\
\hline AI 7.3 & $\begin{array}{l}\text { Implementation- } \\
\text { Plan }\end{array}$ & 2 \\
\hline AI 7.4 & Test Environment & 3 \\
\hline AI 7.5 & $\begin{array}{l}\text { System and Data } \\
\text { Conversion }\end{array}$ & 3 \\
\hline AI 7.6 & $\begin{array}{l}\text { Testing of Changes } \\
\text { AI 7.7 }\end{array}$ & $\begin{array}{l}\text { Fina Acceptance } \\
\text { Test }\end{array}$ \\
\hline AI 7.8 & $\begin{array}{l}\text { Promotion } \\
\text { Production }\end{array}$ & 1 \\
\hline AI 7.9 & $\begin{array}{l}\text { Post- } \\
\text { implementation } \\
\text { Review }\end{array}$ & 3 \\
\hline & Rata-rata & 2,5 \\
\hline
\end{tabular}

Sistem yang baru perlu dibuat untuk pengembangan operasional. Hal ini membutuhkan pengujian di sebuah lingkungan hidup dengan uji data yang relevan, definisi peluncuran dan instruksi migrasi, perencanaan dan promosi aktual untuk produksi pasca implementasi. Hal ini meyakinkan bahwa sistem operasional 
berjalan dengan keinginan dan hasil yang disepakati, lihat tabel 7.

Rata-rata hasil maturity-Level yang dihasilkan adalah 2,5. Dianggap termasuk ke dalam repeatable but-intuitive.

\section{H. Hasil perhitungan}

Dari hasil analisa diatas, diperoleh level kematangan dari setiap proses yang ada dalam tahap Acquire and Implement (AI) dan proses-prosesnya bisa dilihat pada ilustrasi Hasil perhitungan maturity level menggunakan tabel hasil perhitungan Maturity level AI, lihat tabel 8.

Tabel 8 Maturity level AI

\begin{tabular}{|c|c|c|}
\hline Domain & Keterangan & $\begin{array}{c}\text { Hasil } \\
\text { rata }\end{array}$ \\
\hline AI1 & $\begin{array}{l}\text { Identify } \\
\text { Solutions }\end{array}$ & 2.25 \\
\hline $\mathrm{AI} 2$ & $\begin{array}{l}\text { Acquire and Maintain- } \\
\text { Application Software }\end{array}$ & 2.7 \\
\hline $\mathrm{AI} 3$ & $\begin{array}{l}\text { Technological- } \\
\text { Infrastructure } \\
\text { Acquisition Plan }\end{array}$ & 2,25 \\
\hline AI4 & $\begin{array}{l}\text { Enable Operation } \\
\text { andUse }\end{array}$ & 3.5 \\
\hline AI5 & Procure IT Resources & 2,25 \\
\hline AI6 & Manage Changes & 3 \\
\hline AI7 & $\begin{array}{l}\text { Install and Accredit } \\
\text { Solutions and Changes }\end{array}$ & 2,5 \\
\hline & Rata-rata & 2.64 \\
\hline
\end{tabular}

Hasil perhitungan maturity-Level yang dilakukan pada PT CMK khususnya pada beberapa domain AI, menghasilkan nilai sebesar 2,64. Dengan demikian, domain AI pada PT CMK dianggap masih termasuk pada level 2 yaitu repeatable but intuitive.

Tabel 9 Hasil perhitungan Gap Ratarata

\begin{tabular}{|c|c|c|c|}
\hline Domain & \multicolumn{3}{|c|}{ Nilai Maturity level } \\
\hline \multirow{2}{*}{ AI } & Saat ini & Diharapkan & GAP \\
\cline { 2 - 4 } & 2,64 & 3 & $3-2,64$ \\
\hline \multicolumn{4}{|c|}{ Rata-rata } \\
\hline
\end{tabular}

Setelah mengetahui nilai rata-rata Maturity level pada beberapa proses yang terdapat pada domain AI, selanjutnya akan dilakukan analisis kesenjangan terhadap nilai rata-rata Maturity level yang diharapkan yaitu sebesar 3. Hal ini dikarenakan, standar nilai minimal rata-rata Maturity level yang seharusnya dimiliki oleh perusahaan tersebut adalah 3 yaitu defined.

Berdasarkan tabel berikut, diketahui bahwa nilai kesenjangan Maturity level rata-rata yang dimiliki adalah sebesar 0,36. Meski GAP tidak terlalu besar, namun perlu dilakukan penyesuaian terhadap masingmasing domain, lihat tabel 10.

\section{Tabel 10. Hasil perhitungan GAP per domain}

\begin{tabular}{|c|c|c|c|}
\hline \multirow{2}{*}{ Domain } & \multicolumn{3}{|c|}{ Nilai Maturity level } \\
\cline { 2 - 4 } & Saat ini & diharapkan & GAP \\
\hline AI 1 & 3 & 4 & 0.75 \\
\hline AI 2 & 3 & 4 & 0.3 \\
\hline AI 3 & 2,25 & 3 & 0,75 \\
\hline AI 4 & 3.5 & 4 & 0,5 \\
\hline AI 5 & 2,25 & 3 & 0,75 \\
\hline AI 6 & 3 & 4 & 1 \\
\hline AI 7 & 2,5 & 3 & 0,5 \\
\hline
\end{tabular}

Oleh karena itu, maka peneliti akan memberikan beberapa rekomendasi atau masukan pada masing-masing subdomain yang digunakan sebagai bahan pertimbangan dalam peningkatan kerja proses pada masing-masing subdomain, terutama pada proses bagian subdomain yang masih perlu di kembangkan.

\section{Rangkuman temuan}

Dari temuan diatas kami menemukan bahwa perusahaan ini masih memiliki banyak kekurangan yang terbagi diantara beberapa sub domain, yaitu : 
- AI1 Belum ditentukan interface antar manajemen IT dengan business dalam mengidentifikasi dan menetapkan solusi IT.

- AI2 Belum mempunyai prosedur approval yang terdokumentasidan disetujui untuk memastikan semua langkah di-ikuti dan pengecualian yang belum otorisasi.

- AI3 koordinasi infrastruktur teknologi belum ditentukan dan dipelihara.

- AI4 Proses dokumentasi user operasi secara manual dan pemakaian material belum dilihat melalui business perspective perusahaan.

- AI5 Kontrak dan perjanjian kerjasama belum diatur ,dikembangkan dan dikomunikasikan.

- AI6 Penelusuran terhadap perubahan tidak diperbuat oleh golongan yang berpengalaman.

- AI7 Kualitas dari sistem entering production tidak menghasilkan tingkatan yang jelas pada postimplementation problems.

Rekomendasi yang dapat kami berikan berupa pengelolaan IT yang harus lebih memperhatikan bagaimana penggunaan aplikasi mulai dari memanajemen IT, mengatur jalan nya infrastruktur teknologi agar dapat terpelihara, kemudian mengelola proses dokumentasi user operasi secara manual agar dapat berjalan melalui business perspective perusahaan. selain itu, perlu diadakan integrasi terhadap user agar dapat bekera secara maksimal dalam penggunaan aplikasi tersebut. Pihak dari manajemen dan pemimpin IT juga perlu mengadakan kerjasama agar kinerja aplikasi dapat dikembangkan dan dikomukasikan sehingga menghasilkan Maturity level yang diharapkan untuk keperluan PT CMK sesuai dengan standar COBIT 4.1 agar pengelolaan IT dapat berjalan dengan baik.
Dengan demikian berdasarkan hasil perhitungan yang didapat dari hasil rata-rata yang akan dipaparkan pada gambar 2 .

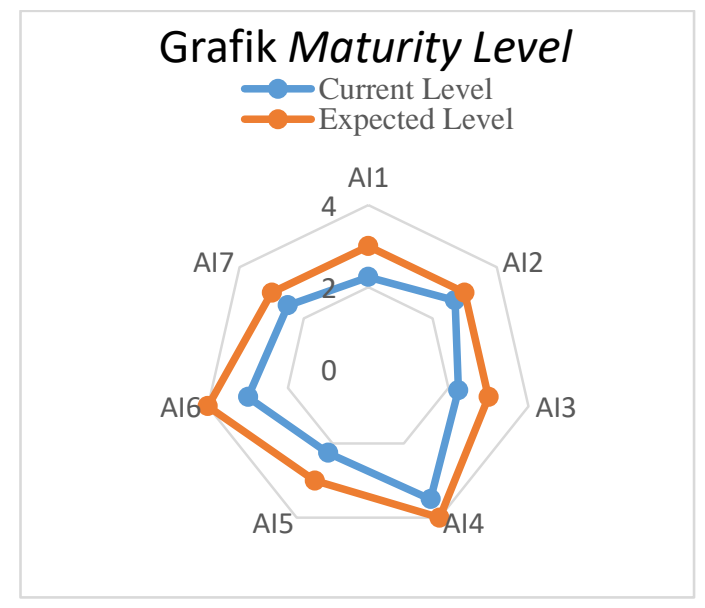

\section{Gambar 2 Hasil perhitungan Maturity level menggunakan grafik}

\section{KESIMPULAN}

Setelah tahap kegiatan audit yang kami lakukan studi kasus di PT Central Mega Kencana. Dapat ditemukan:

- Program developer internal PT Central Mega Kencana dalam melakukan tata kelola teknologi informasi masih belum berjalan secara maksimal dengan framework COBIT 4.1. Sebab tata kelola yang berjalan di PT CMK ini hanya memakai sesuai kebutuhan untuk mendukung berjalannya bisnis di perusahaan.

- Dari hasil audit yang dilaksanakan, pengukuran capability level proccess area acquired and implement pada PT Central Mega Kencana, diperoleh hasil level kapabilitas 2, level rata-rata 2,64, artinya AI 1 - AI 7 (Acquired and Implement) sedang dalam tahap menuju capability level 2 dan masih mencapai 0,64 di atas level 2. Pembulatan ke bawah dipilih sesuai dengan konsep penentuan capability level proses tertentu. Maka dari itu untuk AI1- AI7 capability level masih dianggap 2, sehingga capability level target yang diinginkan adalah level yang sedang ditujunya yaitu level 3 . 


\section{DAFTAR PUSTAKA}

Andry, J. F. dan Christianto, K., 2018. "Audit Mengunakan COBIT 4.1 dan COBIT 5 dengan Case study". Teknosain, Edition-1, ISBN: 978602-6324-95-5.

Ekowansyah, E., Chrisnanto, Y. H, Puspita, dan Sabrina, N. 2017."Audit Sistem Informasi Akademik Menggunakan COBIT 5 di Universitas Jenderal Achmad Yani".Universitas Jenderal Achmad Yani.Cimahi.

Fenny, dan Andry, J. F., 2017. "Audit Sistem Informasi Menggunakan Framework Cobit 4.1 Pada PT Aneka Solusi Teknologi".Universitas Bunda Mulia. Jakarta.

Sulaeman, F. S., 2015. "Audit Sistem Informasi Framework COBIT 5".Teknik Informatika Unsur.

Setiawan, H., dan Mustofa, K., 2013, "Metode Audit Tata Kelola Teknologi Informasi di Instansi Pemerintah Indonesia".Universitas Indo Global Mandiri.Palembang.

Subakti, H., 2012. "Managing Control Object For IT(COBIT) Sebagai Standar Framework Pada Proses Pengelolaan IT". Universitas Respati Yogyakarta.Yogyakarta.

Tjhin, V. U., 2014. "Audit Domain Acquire And Implement Dengan Cobit 4.1 Pada PT Erajaya Swasembada Tbk ComTech". Vol. 5: 10861095.Jakarta barat.

Wella., 2016. "Audit Sistem Informasi Menggunakan COBIT 5.0 Domain DSS pada PT Erajaya Swasembada, tbk". Universitas Multimedia Nusantara.Tangerang. 